\title{
Escolas especializadas: uma análise sobre sua subsistência frente à politica pública de inclusão
}

\author{
Specialized schools: an analysis about their subsistence facing the public policies of \\ inclusion
}

Cláudia Tavares do Amaral ${ }^{1 *}$, Juliany Alves Castro²

\begin{abstract}
RESUMO
A atualidade ainda é marcada pelas discussões sobre o processo de inclusão de alunos nas escolas de ensino regular, porém, há muitos profissionais e muitas famílias que acreditam que os alunos público-alvo da Educação Especial devem ser direcionados para escolas especializadas, pois, assim, terão suas necessidades atendidas de forma mais abrangente. Este artigo insere-se nesse contexto e tem como objetivo analisar a existência de escolas especializadas perante a legislação que enfatiza a inclusão e a obrigatoriedade das escolas regulares de receberem estudantes com deficiência. Como metodologia, a pesquisa teve cunho bibliográfico e documental, pautando-se, sobretudo, em autores como Mendes (2006, 2010, 2019), Pletsch (2012) e Silva (2006), que tratam da temática e nos fornecem elementos para subsidiar o estudo. Os resultados apontam para diferenciações muito evidentes nas escolas especializadas e nas escolas regulares, principalmente diante da postura pedagógica e metodológica com esses alunos. Remetem à necessidade de maior investimento em formação específica dos professores que atuam nas escolas regulares, para que seja possível diminuir impactos negativos na inclusão dos alunos com deficiência nesse espaço, e para minimizar preconceitos de segregação histórica que marcam aquelas pessoas com deficiência, fazendo com que sejam direcionadas às escolas especializadas, mesmo quando não oferecem condições de socialização e interação com alunos que não possuem deficiência.
\end{abstract}

Palavras-chave: Educação Especial; Segregação na educação; Legislação educacional.

\begin{abstract}
Current times are still characterized by discussions concerning the students' inclusion process at mainstream schools, however there are many professionals as well as families that believe the target students of Special Education should be directed towards specialized schools, since therefore they would have their needs met more broadly. This article inserts itself into this context and has as a purpose analyze the existence of specialized schools facing the legislation that emphasizes inclusion as well as the requirement of regular schools to receive students with disabilities. As a methodology, this research was bibliographic and documental, basing itself overall into work of authors such as Mendes (2006, 2010, 2019), Pletsch (2012) and Silva (2006), who deal with the theme and provide us with elements to subsidize the study. The results point towards extremely evident differentiation at specialized schools and regular schools, especially with respect to the methodological and educational stances towards these students. It points to a need for greater investment into specific training of teachers that work in regular schools, so that it is possible to diminish negative impacts in the inclusion of students with disabilities onto this space, as well to minimize historical segregation prejudices which mark those people with disabilities, causing them to be directed towards specialized schools, even when these do not offer conditions for interaction and socialization with students that do not have disabilities.
\end{abstract}

Keywords: Special education; Segregation in education; educational legislation.

\footnotetext{
1 Faculdade de Educação da Universidade Federal de Catalão - UFCAT.

* E-mail: claudiatamaral@ gmail.com

${ }^{2}$ Secretaria Municipal de Educação de Santa Cruz de Goiás.
} 


\section{INTRODUÇÃO}

O tema Educação Especial ainda desperta novas inquietações e adaptações, visto que há aqueles que defendem sua forma expressa na inclusão e os que militam pela permanência de atendimento educacional somente no âmbito de escolas especializadas (ROMERO; SOUZA, 2008; MENDES, 2006, 2019; BAPTISTA, VIEGAS, 2016; RABELO, KASSAR, 2018). O fato é que a inclusão deve ocorrer, independente se no âmbito da escola regular ou da especializada, já que os alunos com deficiência, transtornos globais do desenvolvimento e altas habilidades e superdotação fazem parte do universo daqueles que são amparados pelas garantias educacionais e carecem de um atendimento compatível com suas necessidades reais (BRASIL, 1996, 2008).

Nesse sentido, questionamos qual seria o melhor lugar para que esses alunos fossem incluídos e não apenas integrados no contexto escolar. Este artigo objetiva analisar a subsistência de escolas especializadas frente às atuais políticas que reforçam a preferência de matrículas desses alunos nas redes de ensino regular. Para a tessitura do presente texto, partimos de alguns questionamentos: a) quais as principais disparidades encontradas entre as escolas comuns e as especializadas? b) Mesmo diante da legislação, qual a motivação dos pais ao procurarem as escolas especializadas para realizar as matrículas de seus filhos? e c) Os professores das escolas especializadas, de forma geral, recebem um suporte diferenciado, se comparado aos da escola comum?

Esta pesquisa é de cunho bibliográfico, pois busca refletir sobre a temática a partir do que foi produzido enquanto conhecimento na área em pesquisas já realizadas (MARCONI; LAKATOS, 2017). Lançamos mão, também, da pesquisa documental, uma vez que se amparou na legislação existente, tal como na Lei de Diretrizes e Bases da Educação Nacional - Lei n. 9394/96 (BRASIL, 1996), na Constituição Federal de 1988 (BRASIL, 1988) e no Decreto n. 7611/2011, que dispõe sobre a educação especial e o atendimento educacional especializado (BRASIL, 2011).

É de compreensão pública que a Educação Especial está presente como tema de pauta nas políticas públicas educacionais que estão sendo construídas, e "[...] em nenhum outro momento da história da Educação brasileira, os direitos sociais e educacionais de 
pessoas com deficiências e outras condições atípicas do desenvolvimento estiveram tão presentes nas políticas públicas" (PLETSCH, 2012, p. 32).

Não se pode negar que alguns direitos desses sujeitos já eram resguardados antes da Constituição Federal de 1988 (BRASIL, 1988) e da Lei n. 9.394/1996 (BRASIL, 1996). Entretanto, as referidas normas jurídicas se evidenciaram no tocante à Educação Especial, sobretudo a partir do governo do então presidente Lula (2003 - 2011), quando ocorreu um período de mudanças significativas na estrutura e no funcionamento de instituições com adequação para o atendimento educacional às pessoas com deficiência.

A aprovação do Decreto $n^{\circ}$ 6.571/08 (BRASIL, 2008) e sua revogação pelo Decreto $\mathrm{n}^{\mathrm{o}}$ 7.611/11 (BRASIL, 2011) apontam, entre outros aspectos, que o Atendimento Educacional Especializado (AEE) deve ocorrer sob dois modelos: a) em salas de recursos multifuncionais instaladas em escolas comuns da rede regular de ensino; e b) em centros de AEE formados por escolas especiais convertidas em centros de suporte educacional. Ambos os modelos devem funcionar como complemento e suplemento ao ensino comum, e não como espaços substitutivos de escolarização, conforme ocorria/ocorre, historicamente, em escolas especiais e nas classes especiais (PLETSCH, 2012; MENDES, 2010, 2019).

Diante de uma legislação que, preferencialmente, aponta para que a escolarização de alunos público-alvo da Educação Especial ocorra no ensino regular, tendo entre os direitos o Atendimento Educacional Especializado (AEE), como subsistem as escolas especializadas? Nesse sentido, o presente artigo segue a fim de refletir sobre essa situação atual emergente que, de certa forma, extingue a escolarização desses alunos em ambientes especializados.

\section{A ESCOLA REGULAR E AS ESCOLAS ESPECIAIS: BREVE HISTÓRICO}

As instituições de Educação Especial começaram a se constituir no Brasil por volta do século XIX, baseando-se na experiência europeia. Tal fato ocorreu em 1854, com a criação do Instituto dos Meninos $\operatorname{Cegos}^{3}$, comandado por Benjamim Constant, e, em 1857, com o Instituto dos Surdos-Mudos ${ }^{4}$, sob a direção do francês Edouard Huet (MAZZOTTA, 2005). Para Teixeira (1968), a constituição dessas instituições conhecidas

\footnotetext{
${ }^{3}$ Atual Instituto Benjamim Constant (IBC).

${ }^{4}$ Atual Instituto Nacional de Educação de Surdos (INES).
} 
como pioneiras, o que foi algo emblemático, pois nessa época não se valorizava de forma tão marcante como eram os deficientes.

Em 1874, foi criado o Hospital Juliano Moreira na Bahia, primeiro passo para que os médicos oferecessem assistência às pessoas que apresentavam deficiência intelectual. Já em 1877, foi criada a Escola México, no Rio de Janeiro, cujo objetivo era atender pessoas com deficiência física e intelectual. Foi assim que se teve a origem de duas vertentes diferenciadas para a Educação Especial no Brasil, a "médica-pedagógica" e a psicopedagógica, que é definida por Januzzi (1992, p. 59) como "médico-pedagógica: mais subordinada ao médico, não só na determinação do diagnóstico, mas também no âmbito das práticas escolares [...]”. E a psicopedagógica “que não independe do médico, mas enfatiza os princípios psicológicos [...]".

Durante o período colonial, porém, não havia grande preocupação com a situação em que se encontravam as pessoas com deficiência, o que também podia ser visto em relação à educação da população em geral e, por isso, existiam instituições que atendiam apenas àqueles sujeitos que apresentavam casos mais graves de deficiência, fazendo com os que apresentavam deficiências mais brandas não fossem alvo de escolarização, o que era muito comum entre a sociedade da época, com a maioria ainda vivendo no ambiente rural (MENDES, 2006; SILVA, 2006, 2010).

Após a Proclamação da República, em 1889, e com a volta de profissionais que foram estudar na Europa, houve um interesse frente à modernização do país, sendo que, em 1891, o federalismo estabeleceu as responsabilidades sobre a política educacional brasileira, colocando nas mãos de estados e municípios as do ensino primário e profissionalizante, e à união, o ensino secundário e superior (ARANHA, 2005).

Pereira (1993) reconhece que, por volta do período de 1900, predominava ainda apenas os estudos médicos sobre as crianças que apresentam prejuízos mais graves em sua educação. Nesse ano, Carlos Eiras apresentou sua pesquisa com o título "A Educação e Tratamento Médico-Pedagógico dos Idiotas" ${ }^{5}$, em que analisava a necessidade de uma educação especializada direcionada às pessoas com deficiência intelectual. De acordo com Mendes (2010, p. 94):

\footnotetext{
${ }^{5}$ Inicialmente, o termo "Idiota", do grego "idiótes", refere-se à pessoa leiga, sem habilidades profissionais, mas, aos poucos, o termo evoluiu de forma depreciativa para caracterizar uma pessoa ignorante, simples, sem educação, indicando um indivíduo tolo, imbecil, desprovido de inteligência e de bom senso. Portanto, o título da obra do autor referia-se à educação e ao tratamento dado a esses indivíduos que, supostamente, não possuíam inteligência.
} 
Este interesse dos médicos pelas pessoas com deficiências teria maior repercussão após a criação dos serviços de higiene mental e saúde pública, que em alguns estados deu origem ao serviço de Inspeção médico-escolar e à preocupação com a identificação e educação dos estados anormais de inteligência.

Autores como Silva (2006, 2010) e Mendes (2010) reconhecem que essas medidas foram tomadas por estarem ligadas ao higienismo e à saúde pública, movimento que durante o século XIX reunia médicos que procuravam influenciar o Estado a investir na área de saúde pública, tida como elemento básico para melhorar a qualidade de vida da população. Nesse período, Mendes (2010) esclarece que a deficiência era vista como uma doença, geralmente causada pela sífilis, tuberculose, doenças venéreas, pobreza e falta de higiene.

No período que compreende as duas primeiras metades das décadas do século XX, o Brasil enfrentou um processo de estruturação da república, em que ficaram evidentes as diferenças existentes entre as regiões. Essas diferenças deram origem a inúmeras transformações político-sociais que surtiram efeitos sobre a educação, principalmente porque, até a Primeira Guerra Mundial, havia uma educação elitista no país e grande parte das pessoas pertencentes às classes populares não tinha nenhum acesso à escola (Teixeira, 1977).

Com o findar da Primeira Guerra Mundial (1914-1918), ocorreu um crescimento acelerado da industrialização no país, provocando um novo modelo econômico e trazendo a necessidade de mão de obra especializada. Foi nesse contexto que, a partir da década de 1930, a escola primária pública começou a se difundir, isso porque o índice de analfabetismo no país estava próximo a 80\%. Teixeira (1968) ressalta que se passou a reduzir o tempo de estudo e a criar novos turnos, para que as pessoas pudessem frequentar a escola.

No caso da vertente psicopedagógica, ela também sofre influência das mudanças ocorridas no âmbito legal, com base no movimento da Escola Nova. Não só no Brasil, mas em um contexto mundial, surgiram várias escolas que buscavam diminuir a rigidez, o tradicionalismo e a tendência intelectualista, que já não mais conseguiam responder às necessidades sociais e às transformações que nela estavam em curso. Em relação ao movimento da Escola Nova, Mendes (2010, p. 96) considera:

Os princípios do movimento escola-novista [...] foram a crença no poder da educação, o interesse pelas pesquisas científicas, a preocupação em reduzir as desigualdades sociais e em estimular a 
liberdade individual da criança. No Brasil seus ativistas defendiam tanto a necessidade de preparar o país para o desenvolvimento através de reformas educacionais, quanto o direito de todos à educação, e por isso pregavam que a construção de um sistema estatal de ensino público, laico e gratuito, seria o único meio efetivo de combate às desigualdades sociais da nação.

A Escola Nova impulsionou diversos estados a promoverem reformas pedagógicas e, com isso, trouxe a possibilidade de que a psicologia pudesse introduzir-se no mundo da educação, utilizando testes de inteligência que fossem capazes de analisar a deficiência intelectual.

Em 1913, Clemente Quaglio, da Escola Normal de São Paulo, utilizou os primeiros dados estatísticos afirmando que entre 150 crianças de escolas públicas, $13 \%$ apresentavam dados anormais de inteligência. Esses estudos influenciaram as escolas regulares a lançarem um olhar diferente, assim como houve uma preocupação nacional com a identificação de casos leves de "anormalidade de inteligência". No entanto, essa preocupação só acontecia nas escolas públicas, pois os casos mais graves nem chegavam a fazer parte de sua realidade (JANNUZZI, 1992). Em 1915, iniciaram a publicação de trabalhos sobre a educação para pessoas com deficiência.

Entre os escolanovistas estão figuras como Francisco Campos, de Minas Gerais, responsável pela vinda de professores psicólogos europeus para o Brasil, cujo objetivo era ministrar cursos a outros professores. Entre os estrangeiros, destacou-se Helena Antipoff ${ }^{6}$, que chegou ao país em 1929, psicóloga russa que influenciou profundamente a Educação Especial brasileira (ROCHA, 2017) e foi responsável pela criação, em 1939, de uma escola para crianças excepcionais, na fazenda do Rosário, cujo objetivo era unir

\footnotetext{
6 “Helena Antipoff nasceu na Rússia em 1892 e, em 1908, mudou-se para França. No Laboratório de Psicologia da Universidade de Paris, participou da padronização dos testes de nível mental de crianças, elaborada por Alfred Binet e Théodule Simon. Nesse período, conheceu Edouard Claparède, que a convidou para fazer parte do Instituto Jean-Jacques Rousseau, na Suíça, onde concluiu o curso de Psicologia, com especialização em Psicologia da Educação. Sua experiência profissional teve início na Maison Des Petits, escola anexa ao Instituto Jean-Jacques Rousseau. Os princípios da "Escola Sob Medida"6, o método de "Experimentação Natural"7 e os testes de inteligência, elaborados por Alfred Binet e Théodule Simon, fundamentaram sua prática pedagógica. Retornando à Rússia, em 1916, trabalhou com crianças órfãs, vítimas da Primeira Guerra e da Revolução Russa. Antipoff fez um diagnóstico do sistema de ensino mineiro [...] destacando três problemas: 1) não ocorria, nas escolas, a orientação profissional das crianças; 2) a formação física, moral e intelectual das crianças, ao saírem da escola primária, apresentava-se incompleta; 3) havia crianças que se encontravam "em perigo moral"8. Para a educadora, essas questões estariam relacionadas à duração da escolaridade que, se comparada a outros países, era menor. O problema da criança "em perigo moral", principalmente, seria resultado do próprio sistema de ensino e, fazendo uma crítica à pedagogia tradicional, conclamou a pedagogia experimental” (RAFANTE, LOPES, 2009, p. 229).
} 
a escola e a comunidade rural, dando início ao Complexo Educacional da Fazenda do Rosário. De acordo com Mendes (2010, p. 97):

Além dessas iniciativas participou ativamente do movimento que culminou na implantação da Associação de Pais e Amigos dos Excepcionais, em 1954, além de influenciar a formação de um contingente grande de profissionais que passaram a se dedicar à área nos anos posteriores.

É necessário ponderar que, mesmo sendo uma vertente que defende a atenuação das desigualdades sociais, assim como enfatiza as características individuais e a necessidade de um ensino adequado e especializado para esses indivíduos, foi, porém, uma opção que excluiu os que eram considerados como diferentes das escolas regulares dessa época, porque, mesmo com a obrigatoriedade e gratuidade do ensino, aqueles que não atendiam às expectativas escolares eram designados a instituições que lhe ofereciam uma educação mais adequada às suas necessidades.

De forma resumida, até 1935, a educação destinada aos sujeitos com deficiência intelectual era marcada pela ausência de escolas, por conceituações sobre deficiência contraditórias e imprecisas, classificação restrita ao nível de discurso, e os poucos métodos utilizados na educação desses indivíduos advinham das concepções francesas e, posteriormente, da Europa como um todo e norte-americana. O Brasil, segundo Cunha (1998), andava na contramão dos outros países, que criavam instituições, implantavam escolas especiais comunitárias e classes especiais nas escolas públicas, enquanto isso, no Brasil, predominava uma espécie de desinteresse com a conceituação, com a classificação e com a criação de serviços especializados a essas pessoas.

Na década de 1930, criou-se a expressão "ensino emendativo", que era aquele destinado a tirar defeitos e suprir falhas que advinham da possível anormalidade dos alunos (JANUZZI, 2004). Durante o período de 1937 a 1945, a política do Estado Novo favoreceu o Ensino Superior e, com isso, o retrocesso no processo de democratização do ensino.

Durante o período acima citado ocorreu, também, uma lenta evolução do número de novos estabelecimentos destinados ao atendimento dos indivíduos com deficiência, todavia, a proliferação de classes especiais ficou evidente. O governo demonstrava certo descaso com a educação de pessoas com deficiência e, por isso, desencadeou uma tendência à privatização desse setor (Cunha, 1998). 
O período da Segunda República ocorreu de 1945 a 1964, quando aconteceu a institucionalização da filantropia ao abordar a questão da pessoa com deficiência. Nesse período, também se fortaleceu a ideia da educação como um direito de todos. Com isso, de 1950 a 1959, o aumento do número de instituições destinadas às pessoas com deficiência intelectual foi tão expressivo que chegaram, segundo Jannuzzi (1992), em volta de 190 estabelecimentos no final de 1950, com grande maioria pública, havendo o destaque para a criação da primeira Associação de Pais e Amigos dos Excepcionais (APAE), em 1954, no Rio de Janeiro, influenciada por norte-americanos, e:

A partir de 1958 o Ministério de Educação começou a prestar assistência técnica-financeira às secretarias de educação e instituições especializadas, lançando as campanhas nacionais para a educação de pessoas com deficiência: Campanha para Educação do Surdo Brasileiro (CESB), em 1957; Campanha Nacional de Educação e Reabilitação dos Deficitários Visuais (CNERDV), em 1958; Campanha Nacional de Educação do Deficiente Mental (CADERNE), em 1960. Enquanto isso se intensificava o debate sobre a educação popular, a reforma universitária e os movimentos de educação popular (MENDES, 2010, p. 99).

A Lei de Diretrizes e Bases, de 1961 (n 4024), utilizou a expressão “educação de excepcionais", desde então, deu-se o marco para o início das ações do poder público destinado à educação especial, principalmente porque, antes dessa lei, as iniciativas eram regionalizadas e isoladas da política educacional nacional. A partir daí, as instituições privadas de estrutura filantrópica cresceram, tanto as APAEs como a Sociedade Pestalozzi que, em 1967, chegavam a 16 instituições em todo Brasil, as quais surgiram porque ainda era persistente a omissão do poder público em relação ao público-alvo da educação especial, mas recebiam verbas do governo, destinadas à Educação Especial, o que exonerou a educação de sua responsabilidade (MENDES, 2010).

As escolas públicas estendiam cada vez mais as matrículas às classes populares, mas, com isso, os índices de fracasso escolar aumentaram, e muitas das justificativas remetiam à existência de deficiência intelectual de grau leve entre muitos alunos, o que passou a justificar, também, a criação de classes especiais nas escolas públicas (FERREIRA, 1992). Esse e outros fatos fazem com que os historiadores deem à década de 1970 o marco inicial da institucionalização da educação especial, pois passou a estar presente em textos legislativos, nas associações e em estabelecimentos, envolvendo a área pública nessa questão. 
O período da Ditadura, que se iniciou em 1964, foi marcado pela evolução dos serviços de assistência, sendo que, em 1969, já existiam mais de 800 estabelecimentos destinados às pessoas com deficiência intelectual. Tal proliferação de instituições fez, segundo Mendes (2010), com que houvesse a necessidade de construção de bases legais e técnico-administrativas para o desenvolvimento da Educação Especial brasileira, que já se baseava na LDB de 1961 e foi reafirmada pela LDB de 1971, que considerava que eram alvo da Educação Especial aqueles indivíduos que possuíam deficiências físicas ou mentais e que estavam em atraso considerável quanto à idade regular de matrícula e, ainda, os superdotados, fazendo com que, segundo Kassar (1988), se instituísse uma associação da educação especial ao fracasso escolar.

Em 1973, foi criado o Centro Nacional de Educação Especial (CENESP), junto ao Ministério da Educação, que se tornou o primeiro órgão educacional do governo destinado a definir políticas para a educação especial. Mesmo assim, o período da ditadura ainda é marcado pelo caráter assistencialista-filantrópico quando se fala em educação especial. É, porém, segundo Mendes (2010), com a redemocratização do país que acontece o despertar da consciência da população em relação à Educação Especial no Brasil. De acordo com a autora,

Com o fim do governo militar e o advento da Abertura Política, novas iniciativas surgiram no panorama da Educação Especial no Brasil, principalmente ao longo da segunda metade da década de oitenta. Em 1985, o CENESP a elevado a condição de Secretaria de Educação Especial e é instituído um comitê nacional para traçar política de ação conjunta, destinada a aprimorar a Educação Especial e a integrar, na sociedade, as pessoas com deficiências, problemas de conduta e superdotados (MENDES, 2010, p.101).

Na Constituição de 1988, citou-se a educação de pessoas com deficiência como aquela que deveria acontecer, preferencialmente, na rede regular de ensino, garantindo também o direito ao atendimento educacional especializado. E, depois de 1990, a implantação da política de Educação Especial passou para as mãos da Secretaria Nacional de Educação Básica (SENEB), que passou a fazer parte do Ministério da Educação e Desporto (MEC), utilizando a sigla SEESP.

É preciso considerar ainda que, na década de 1990, o problema da repetência era um dos mais graves na educação, levando a se considerar que ela era provocada pela deficiência intelectual, tornando-se um padrão de diagnóstico, o que induzia muitos alunos a serem destinados a serviços de educação especial. Havia, segundo Ferreira 
(1989), uma confusão entre a deficiência e as condições sociais em que viviam os indivíduos, no entanto, ambas conduziam os alunos ao fracasso escolar. Essas condições fizeram com que métodos de ensino equivocados fossem adotados nas instituições, como afirma Mendes (2010, p. 103), ao dizer que:

[...] a didática assumia a infantilização do aluno com deficiência, a partir de um raciocínio equivocado que supunha que eles deveriam aprender habilidades típicas do nível pré-escolar, para adquirir "prontidão" para a alfabetização. A estratégia instrucional se resumia a treinar os alunos em atividades supostamente preparatórias, com ênfase na repetição.

Logo no começo da década de 1990, os alunos com deficiência tinham a opção de frequentar a escola especial filantrópica, que não garantia sua escolarização, ou a classe especial nas escolas públicas estaduais que, para Cunha (1998), servia mais como um mecanismo de exclusão do que, realmente, para escolarizar esses alunos.

$\mathrm{Na}$ Educação Especial buscava-se recuperar ou remediar as etapas que faltavam ao aluno, centralizando os problemas no indivíduo, considerando que suas incapacidades estavam ligadas ao processo cognitivo subjacente. Tudo isso fez com que, até o final da década de 1990, houvesse um processo de isolamento do indivíduo que era considerado deficiente daqueles que eram considerados normais, buscando-se efetuar um diagnóstico, mas sem nenhum tipo de discussão sobre o currículo ou as estratégias institucionais para trabalhar com essas pessoas. A consequência desse processo foi o fortalecimento do estigma da deficiência e o fortalecimento da exclusão social, reduzindo as possibilidades que esses sujeitos tinham de aprender e de se desenvolver (FERREIRA, 1989).

A partir do século XIX, iniciativas isoladas passaram a ser observadas dentro da educação especial, mas foi somente a partir de 1970 que a sociedade brasileira passou a responder de forma mais efetiva e positiva a essa questão, momento em que a teoria da inclusão passou a se fortalecer, em detrimento da ideia de que a segregação pudesse atender melhor às necessidades educacionais dos alunos. Aí, as instituições especializadas passaram a expandir-se, como afirma Prieto (2006, p. 67-68), ao dizer que:

[...] Todavia foi também a partir dessa mesma época que houve a expansão mais expressiva de serviços de atendimento especializado paralelos ao ensino regular, de cunho filantrópico e nem sempre de caráter educacional. Convivemos desde então com o ensino traduzido pela dicotomia comum e especial, sem que tenhamos condições de avaliar as tensões daí decorrentes. 
Tudo isso faz com que seja preciso lançar um olhar sobre as escolas regulares e o que elas oferecem ao indivíduo com deficiência, e sobre as instituições especializadas diante desse processo de inclusão, o que gera um intenso debate sobre a necessidade ou não de sua existência diante dessa busca pela sociedade inclusiva.

Foi somente a partir da década de 1970 que se fortaleceu a ideia de que os alunos com deficiência precisavam ser incluídos na sala de aula regular, acabando com esse processo de segregação que criava estereótipos, estigmas e separação daqueles que possuíam algum tipo de deficiência. Essa teoria evoluiu ao ponto de fazer com que, hoje, seja comparada à integração escolar na década de 1930, ou seja, como uma necessidade real e latente. Para Mendes (2010), a inclusão é um avanço necessário para a Educação Especial no Brasil e não há, nem na perspectiva filosófica nem na política, algo que possa questionar a necessidade de que alunos com e sem deficiência possam conviver em um mesmo espaço, trocando experiência e desenvolvendo sua aprendizagem.

O processo de inclusão tão divulgado e debatido nas últimas décadas fez com que surgissem dois modelos básicos de educação destinada às pessoas com deficiência: um promovido por instituições de caráter assistencialista e filantrópico, patrocinadas por diferentes instâncias do setor público; e outro oferecido pelo sistema de ensino regular, que é fragilizado, no sentido de que nem sempre o aluno com deficiência encontra infraestrutura e profissionais qualificados para que possam ter acesso a uma educação de qualidade, que respeite suas necessidades e limitações (MENDES, 2019; RABELO, KASSAR, 2018; NEVES, RAHMEL, FERREIRA, 2019).

Prieto (2006) afirma que o debate da atualidade está sendo sobre como as instituições de ensino regular que podem receber aqueles que possuem deficiência estão permitindo a inclusão desses alunos, o que, de certa forma, também gera sua inclusão social; e as instituições de ensino especializado, que têm sido questionadas em sua existência, uma vez que muitos acreditam que elas não sejam necessárias na sociedade inclusiva. Há, porém, aqueles que, diante das limitações que a educação brasileira apresenta, defendem a manutenção dos serviços educacionais paralelos, colocando nas mãos dos pais a escolha pela melhor instituição que possa atender seus filhos.

$\mathrm{Na}$ verdade, ainda não se tem um consenso sobre o papel das instituições especializadas na educação das pessoas com deficiência, sendo que há aqueles que acreditam que elas precisam existir, porém, para utilizar seus conhecimentos a serviço do 
ensino comum, e outros defendem sua utilização diante de casos e situações que a escola comum não pode atender.

Assim como demonstra a Constituição de 1988, a presença na sala de aula regular deve existir sempre que for possível, ou seja, existem sujeitos que não poderão estar na sala de aula regular, estes, têm o direito de frequentar uma instituição especializada, o que, obviamente, deixa claro que essas instituições não podem deixar de existir, a não ser que, dentro da sala de aula comum, haja profissionais qualificados para trabalhar com deficiências severas, aquelas que impossibilitam o aluno de frequentar essas instituições, por essa razão, as sessões especiais seriam uma exceção, recomendando-se, assim, a escola regular (NERES, 2010).

\section{CONCLUSÕES}

Analisando o contexto histórico que envolve as escolas especializadas e as regulares, observa-se que o Brasil teve um processo muito lento no que se refere à criação de instituições que atendessem às necessidades educacionais desses indivíduos, principalmente porque havia pouca valorização social desses sujeitos, e a sociedade era marcada por profundos preconceitos. Foi aos poucos, com influência de outros países,

que as primeiras instituições foram criadas, porém, segregando esses indivíduos da convivência com aqueles que eram considerados normais. Foram necessárias muitas mudanças para que o direito de se educar juntamente com os demais alunos fossem conquistados por aqueles que possuem algum tipo de deficiência, principalmente na busca do fim dos preconceitos e diante das possibilidades que essa convivência gera para a aprendizagem e o desenvolvimento dessas pessoas.

Assim, o longo percurso da educação, até que se reconhecesse a necessidade de que os alunos com deficiência convivessem com os que não as possuem, fez com que um amplo processo de exclusão fosse criado e, atualmente, a inclusão tem como objetivo minimizar esse processo de segregação dos indivíduos que possuem deficiência, permitindo que eles possam conviver e socializar-se com os outros alunos, sentindo-se parte do grupo e, acima de tudo, valorizados como cidadãos que são. Isto, porém, trouxe também implicações sobre as instituições especializadas, que atendem somente a esse público específico. 
Avaliando as principais disparidades encontradas entre as escolas comuns e as especializadas, observou-se que a escola regular acaba por colocar no professor e no aluno a responsabilidade pelo sucesso/fracasso dos sujeitos com deficiência, contudo, também traz a oportunidade de que eles convivam com alunos que não têm deficiência, que consigam socializar-se, aprender, trocar experiências, enfim, sentirem-se parte do grupo e contribuir para o fim do preconceito e da segregação em relação a quem possui deficiência. Já as escolas especializadas possuem uma infraestrutura mais adequada ao atendimento do indivíduo com deficiência, profissionais com qualificação mais abrangente, mas acabam agindo como segregadoras, porque excluem esses sujeitos do contato necessário com outras crianças e pessoas que não possuem deficiência.

Há motivos variados que levam uma família a procurar escolas especializadas para realizar as matrículas de seus filhos, principalmente com a crença de que suas necessidades serão melhores atendidas, já que são instituições criadas para receber, especialmente, esse tipo de aluno, assim como a descrença de que a educação pública possa oferecer um ensino de qualidade a seus filhos, principalmente pelos problemas históricos que marcam essas instituições. Há, ainda, o medo do preconceito e de que os filhos acabem sendo alvo de brincadeiras de mau gosto e de tantas outras formas de segregação que seriam evitadas em um espaço onde todos eles são iguais, por terem algum tipo de deficiência. Deve-se considerar que falta, a muitos pais, conhecimentos para que possam avaliar melhor os benefícios de uma e de outra instituição.

Em relação aos professores que atuam nas escolas especializadas, observamos que estes possuem formação específica para atender aquele público-alvo, e supõe-se que saibam lidar com suas deficiências e necessidades, além de ter suporte pedagógico e de infraestrutura mais condizente às necessidades dos alunos.

O que fica claro não é a defesa de um ou de outro modelo, mas a necessidade de que o mesmo suporte profissional e de infraestrutura que é dado nas instituições especializadas seja oferecido à sala de aula comum, tendo em vista que é evidente a necessidade da inclusão. No entanto, ela precisa ser feita com qualidade, permitindo que esses alunos com deficiência tenham possibilidade de vencer suas dificuldades, desenvolver-se e exercer sua cidadania da melhor forma possível. E para isso é necessário que ocorra, principalmente, muito investimento.

A escola especializada acaba existindo em uma sociedade onde muitos propõem a existência de uma escola única, que atenda a todos os alunos, sem exceção, mas também 
diante daqueles que acreditam que a democracia existe quando as pessoas têm diferentes opções de atendimento escolar, quando podem ter acesso a recursos especializados que lhes sirvam de complementação e até mesmo de apoio e suporte para que o indivíduo consiga permanecer na classe comum. Isso faz crer que, atualmente, há duas vertentes: aqueles que defendem a inclusão total, e aqueles que posicionam a educação especializada como uma forma de apoiar o ensino comum e facilitar esse processo de inclusão.

Por fim, os dados apresentados, a partir da legislação existente, apontam para diferenciações evidentes nas escolas especializadas e nas regulares, especialmente frente à postura pedagógica e metodológica com esses alunos. É necessário, ainda, melhorar a qualificação dos professores que atuam em escolar regulares, para que seja possível permitir a inclusão dos alunos com deficiência nesse espaço, a fim de minimizar os preconceitos e a segregação histórica que os marcam e faz com que sejam direcionados às escolas especializadas, mesmo quando elas impendem sua socialização e interação com alunos sem deficiência.

\section{REFERÊNCIAS}

BAPTISTA, C. R.; VIEGAS, L. T. Reconfiguração da Educação Especial: análise da constituição de um centro de atendimento educacional especializado. Revista Brasileira de Educação Especial, Marília, v. 22, n. 3, p. 429-442, jul./set. 2016. Disponível em: <http://www.scielo.br/pdf/rbee/v22n3/1413-6538-rbee-22-03-0429.pdf> Acesso em: 27 jun. 2020.

NEVES, L. R.; RAHMEL, M. M. F.; FERREIRA, C. M. da R. J. Política de Educação Especial e os Desafios de uma Perspectiva Inclusiva. Educação \& Realidade, Porto Alegre, v. 44, n. 1, 2019. p. 1-21 Disponível em: <http://dx.doi.org/10.1590/2175623684853>. Acesso em: 17 maio 2021.

BERNADO, E.; MELLO, M. As instituições especializadas e a Meta 4 do PNE 20142024: implicações para a gestão educacional. EccoS - Revista Científica, O(49). p. 1-12, 2019. Disponível em: < https://doi.org/10.5585/eccos.n49.5587>. Acesso em: 15 maio 2021.

BRASIL. Constituição da República Federativa do Brasil: promulgada em 5 de outubro de 1988. Diário Oficial da União: Brasília, 1988.

BRASIL. Lei N. 9394 de 20 de dezembro de 1996. Estabelece as diretrizes e bases da educação Nacional. Disponível em:

<http://www.planalto.gov.br/ccivil_03/leis/19394.htm>. Acesso em: 06 maio 2021. 
BRASIL. Decreto n. 6571 de 17 de setembro de 2008. Dispõe sobre o atendimento educacional especializado, regulamenta o parágrafo único do art. 60 da Lei n. 9394 de 20 de dezembro de 1996, e acrescenta dispositivo ao Decreto n. 6253 de 13 de novembro de 2007. Diário Oficial da União: Brasília, 2008.

BRASIL. Decreto n. 7611 de 17 de novembro de 2011. Dispõe sobre a educação especial, o atendimento educacional especializado e dá outras providências. Diário Oficial da União: Brasília, 2011.

CUNHA, B. B. B. Classes de Educação Especial para Deficientes Mentais: Intenção e Realidade. Dissertação de Mestrado, São Paulo: Universidade de São Paulo, 1988.

FERREIRA, J. R. A construção escolar da Deficiência Mental. Tese de Doutorado, Campinas: Universidade Estadual de Campinas, 1989.

JANNUZZI, G. S. de M. A luta pela Educação do Deficiente Mental no Brasil. 2.a ed., Campinas: Autores Associados, 1992.

KASSAR, M. de C. M. Liberalismo, neoliberalismo e educação especial: algumas implicações. Cad. CEDES. 1998, vol.19, n.46, pp.16-28. Disponível em: https://www.scielo.br/scielo.php?script=sci_arttext\&pid=S0101-

32621998000300003\&lng=en\&nrm=iso\&tlng=pt Acesso em: 14 maio 2021.

MARCONI, M. A.; LAKATOS, E. M. Fundamentos de metodologia científica. 8. ed. São Paulo: Atlas, 2017.

MENDES, E. G. Breve histórico da educação especial no Brasil. Revista Educación y Pedagogía, v. 22, n. 57, 2010. P. 93-109. Disponível em: https://revistas.udea.edu.co/index.php/revistaeyp/article/download/9842/9041/. Acesso em: 14 jan. 2021.

MENDES, E. G. A política de educação inclusiva e o futuro das instituições especializadas no Brasil. Arquivos analíticos de Políticas Educativas. v. 27, n. 22, mar. 2019. Disponível em: https://epaa.asu.edu/ojs/article/download/3167/2217. Acesso em: 4 abr. 2021.

MENDES, E.G. A radicalização do debate sobre inclusão escolar no Brasil. Revista Brasileira de Educação. v. 11, n. 33, set. /dez. 2006. Disponível em: http://www.scielo.br/pdf/rbedu/v11n33/a02v1133. Acesso em: 4 abr. 2021.

NERES, C. C. As instituições especializadas e o movimento da inclusão escolar: intenções e práticas. Tese de Doutorado - Programa de Pós-Graduação em Educação. Faculdade de Educação da Universidade de São Paulo, 2010.

PLETSCH, M. D. A formação de professores para a educação inclusiva: legislação, diretrizes políticas e resultados de pesquisas. Ciências Humanas e Sociedade em Revista, RJ, EDUR, v. 34, n.12, jan / jun, p. 31-48, 2012. 
RAFANTE, H. C, LOPES, R. E. Helena Antipoff e a Educação dos "Excepcionais": uma análise do trabalho como princípio educativo. Revista HISTEDBR On-line, Campinas, n.33, p.228-252, mar. 2009.

REBELO A. S.; KASSAR, M. de C. M. Escolarização dos alunos da educação especial na política de educação inclusiva no Brasil. Inclusão Social, v. 11, n. 1, 2 mar. 2018. Disponível em: http://revista.ibict.br/inclusao/article/view/4079. Acesso em: 15 maio 2021.

ROCHA, L. R. Trajetórias Profissionais e Educação Especial: ressoar da formação de professores por Helena Antipoff na voz de ex-alunas. 2017. Dissertação (Mestrado em Mestrado em Educação) - Regional Catalão.

ROMERO, R. A. S.; SOUZA, S. B. Educação inclusiva: alguns marcos históricos que produziram a educação atual. Educere, 2008. P.1-14. Disponível em: https://educere.bruc.com.br/arquivo/pdf2008/447_408.pdf>. Acesso em: 18 dez. 2020.

SILVA, A. M. da. Educação especial e inclusão escolar: história e fundamentos. Curitiba: IBPEX, 2010.

SILVA, L. M. O estranhamento causado pela deficiência: preconceito e experiência. Revista Brasileira de Educação, Rio de Janeiro-RJ, v. 11, n. 33, set./dez. 2006. p. 424434. Disponível em: https://www.scielo.br/pdf/rbedu/v11n33/a04v1133.pdf. Acesso em: 23 abr. 2021. 